\title{
Interactive comment on "The cumulative effects of forest disturbance and climate variability on baseflow in a large watershed in British Columbia, Canada" by Qiang Li et al.
}

Anonymous Referee \#3

Received and published: 24 July 2016

This paper presented a study on the effect of forest disturbance and climate variability on baseflow changes in a forested watershed. The main finding is that both forest disturbance and climate variability have significant effects on baseflow magnitudes and patterns. The manuscript is on a topic of interest to the journal and the methodology may have practical values. However, the description of the methodology is confusing at parts and the logic in the result section needs to be improved. My suggestion would be major revision.

Specific comments:

1. P6, L11: The elevations here are missing units. 
2. Figure 1: This figure only shows the part of watershed in Canada. Is the study also only considering the Canadian part of the watershed?

3. P11, L13-16: The definitions of Cbf and Cro are described twice here.

4. P15, L3-4: Please revise this part.

Interactive

5. P15, L9: Did you mean "linear"?

comment

6. P15, L14: I'm confused by the word "calibrated" here. Should it be "calculated"?

7. In general, the methodology part of the manuscript needs to be revised to improve the clarity. The order of the sections and how they link to each other may need to be better explained.

8. Figure 9: I assume the authors plot calculated groundwater discharge vs. calculated baseflow here to find breaking points that indicate baseflow changes. Even this method is described in previous studies, the authors may need to briefly explain the logic behind the method here. Also, what is "Pae"?

9. P19, L1-4: Based on figure 4 and 5 , there is no significant forest disturbance in 1972. Is there any other major changes in that period?

10. The conclusion section need to be revised to provide a comprehensive summary of the study, in terms of methodology, discussion and general outcomes.

Interactive comment on Hydrol. Earth Syst. Sci. Discuss., doi:10.5194/hess-2016-291, 2016. 